\title{
Thoughts on 3D printing
}

\author{
HU Jian-feng \\ Institute of Information Technology, Jiangxi University of Technology, Nanchang 330098, China
}

Keywords: 3D Printing; Intellectual property right; Model; Piracy

\begin{abstract}
Facts have proved that, the development of science and technology, is always a double-edged sword. With 3D printing striding forward like a raging fire, intellectual property risk it could cause also surfaced. 3D print easily copy, share, modify functions, and products produced by these functions, are likely trigger a new intellectual property risk.
\end{abstract}

\section{Introduction}

3D printing is a deceptive noun, Massachusetts Institute of Technology (MIT) in 1995 created this term of 3D printing. From the name it can easily be put it into printing technology, in fact, if we understand the specific process of $3 \mathrm{D}$ printing, there can be no doubt put it into the manufacturing category.

\section{Technical principles}

3D printing technology is from photography sculpture and landform forming technology more than 100 years ago, in the last century 80's the embryonic form has appeared, known as "rapid prototyping". It uses powdered metal or plastic which can be adhesive material, through multi-layer printing technology, to built structural parts. This technology is often used in mold manufacturing and industrial design to build model of product. Now manufacturing is the direction of development, the formation of direct digital manufacturing.

Popular speaking, 3D printing is based on digital design documents, is a process manufacturing a three-dimensional object through adding the material layer by layer. At present, 3D printing is mainly two main ways, one is through sedimentary way, raw materials through some syringes or injection or extrusion, the print head spraying liquid, colloidal material or powder raw materials; two is through the adhesive raw materials, adding a certain adhesive in raw material, layer by layer forming by stereo lithography or laser sintering heat or UV curable powder or photosensitive polymer. In fact, 3D print is a rapid prototyping process, the basic essence is the layered manufacturing and adding layer by layer. In the past, the rapid prototyping technology is mainly used for mould manufacturing and some simple structure parts processing, 3D printing can now manufacture complex heart valve, circuit board, firearms and house etc.

\section{Risk: 3D print initiated new piracy danger}

Based on 3D printing principle, we can see the two key points: 3D modeling and product printing. In the modeling phase, it can scan the print object (3D scan) to obtain three-dimensional design or directly from the network to download a three-dimensional design (CAD file). The behavior to scan object directly to get three-dimensional design or download three-dimensional design directly from 
network, may constitute an infringement. And in the printing stage, due to the modeling stage model of the alleged infringement, also led to the possible infringement of intellectual property rights.

(1) the risk of infringement being triggered by 3D scanning

Through 3D scanning, 3D data can be from object and converted to the CAD file for building the model. The model is similar to original object except the size. In essence, the CAD file is scanned 3D object in computer, three-dimensional image in the computer as scanning object, is "imitation" and "copy" of the existing scanned object. From the process point of view, the essence of 3D scanning is a kind of mechanical reproduction behavior of the overall appearance of the scanned object. Therefore, after geting the CAD file, without permission, copy, sell, modify and other use for the documents, are suspected of infringing the intellectual property law. Specifically, the scanning of patented products by modeling behavior, may infringe the copyright.

(2) the risk of download of the CAD file from the network

In addition to the object 3D scanning modeling, more commonly, people download the corresponding CAD file from the internet. If without the author's permission, user is not for purposes of fair use, or modify the model, it may be a violation of the author's right of authorship, revision, integrity, reproduction, and network dissemination of information.

(3) the risk of use of the "illegitimate source" model to print product

As already mentioned, the CAD file in the computer, is essentially a kind of works. Therefore 3D printing the "works", which is actually a behavior of printing and copy of the works. Therefore, if the model has no "legal origin", it will inevitably lead to acts of infringing the copyright of the original author. I

(4) the CAD file has legal origin, but print beyond reasonable range

Even if the CAD file has a "legal origin", but if user print products outside of some scope, it also infringes the intellectual property rights. With the development of 3D printing technology, many enthusiasts designed 3D model and uploaded it to the network for the purpose of learning and research, but are often accompanied by the conditions of use: for example the limited use of objective, scope and quantity, in order to limit people for large-scale production and sale.

(5) whether is the 3D print of art illegal?

$3 \mathrm{D}$ printing can copy anything, and will become a tool for making art forgery? The product from 3D print can only be classified as a life art type, and can not be compared to the traditional art, they are not in the same level. Printing products is very different with the original works in color and texture.

\section{Regulation on the intellectual property risk prevention}

3D printing has been considered to be "social manufacturing" mode of production, its significance not only lies in changing the distribution of the mode of capital and work, but also because it can change the rules of the existing intellectual property rights. How to prevent the intellectual property risk of 3D printing, prevent everyone at home offering "workshop", become the key to reduce potential legal risks, and to promote the social civilization and progress.

Aclear legislative for the "copy" range of behavior and "CAD file" legal status. Technology development speed is far greater than the formulation of the scope of legal constraints. The legal status and ownership of CAD model are not clear. The copyright protection need to be extended to cover the function objects include design elements, making clear the nature of the CAD model in the copyright law, the provisions of its copyright by scanning products "source" of intellectual property rights, so that it can effectively regulate the behaviors of copy, sell, modify the CAD model. 
Increasing investment, encourage, support research on 3D print controling technology. A "print control system" technology can restrict users to print for personal use. In addition, 3D printing industry also can learn the mean of binding implementation of "model" and "printer" from electronic music and electronic book industry.

Establish 3D model database, adopt more stringent 3D printing industry standard. Intellectual property management departments of the state can introduce a strict 3D printing industry norms for 3D printing industry, mandatory 3D printer manufacturers in the printer installation corresponding "control" system, so that the printer before printing, automatic networking to compare the 3D model to be printed and registered models of the database, in a consistent model of the case, to ban 3D printer work, or only to print products within a certain number. Intellectual property risk will be nipped in the bud.

\section{Thinking: moral risk triggered by the excessive protection on the intellectual property of 3D printing}

Balance between public interests and private interests. In the theory of "balance of interests", each law principle and concrete system reflects the thinking and method to solve the conflict between private interests and public interests, which maintains the balace state between private interests and public interests. The purpose of legislation of intellectual property rights is to promote scientific and technological innovation, increase productivity, and promote the dissemination and use of science and technology, so as to realize the balance of protection of private interests and public interests.

However, paradoxically, limit of knowledge technology itself is a risk: one is the risk of conflict brought by right boundary. For example, in the field of network copyright, definition of proprietary rights and public domain, relationship between digital content and communication technology, the communication between the intellectual achievements and traditional cultural resources, are the legal issues brought by the Internet or the social risk. Two is the risk brought by the technology exclusive use. For example, in the field of gene patents, the use and development of gene food, gene pharmaceutical, gene animal and gene plant gene can lead to changes of human itself and human living environment. This change is mainly to improve and progress, but also implies the negative effect.

Synthetic cheap anticancer drug can be produced by the 3D printing. The problem is, until the establishment of the intellectual property rights protection system for 3D printing, will poor printing organs, life-saving drugs and food be violate intellectual property rights?

Are 3D printing products the scope of protection?. The core of patent protection is the determination of infringement of the patent right. The object of patent protection is the industrial method or industrial products, because 3D printing is using layers of stacked, different with the traditional cutting raw materials or by mould manufacturing, unless the patent method itself involves $3 \mathrm{D}$ printing method, otherwise the 3D printing almost not infringe the patent methods.

Different with traditional producing methods, 3D printing can form the product integral once. For example the production of a toy car, the traditional method, from various parts to production and assembly, but the $3 \mathrm{D}$ printing through the designing document and setting the parameters, can print out the toy car one-time without part. 


\section{Conclusion}

3D printing is a great technological change, which may subvert the existing mode of production. As the patent system, for the purpose of protection of technological innovation and promoting the advancement of productivity, the promotion of 3D printing will bring many challenges.

\section{Acknowledgements}

This work was supported by Natural Science Foundation of Jiangxi Province [No 20142bab207008], project of Science and Technology Department of Jiangxi Province [No 2013BBE50051] and project of Jiangxi[No. XL1406].

\section{References}

[1] http://zh.wikipedia.org

[2] http://gz.ifeng.com

[3] http://www.ifanr.com/

[4] Henry C.Mitchell, The Intellectual Commons: Toward an Ecology of Intellectual Property, Maryland Lexington Books 2005. 